\title{
Caries Management - Science and Clinical Practice
}

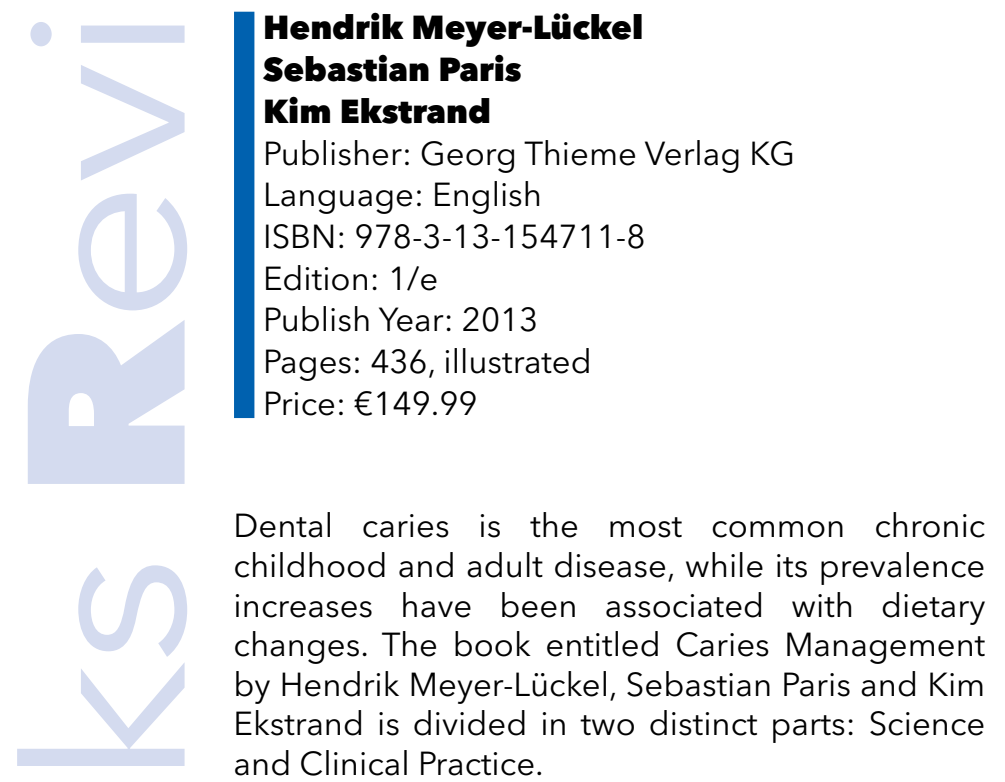

The science part is divided into 23 chapters.

First it presents information on the ecology of the oral cavity, etiology, pathogenesis, clinical histology and appearance of caries, followed by the description of diagnosis methods and caries risk assessment

After determining the risk of caries, the book describes noninvasive methods for caries management, such as biofilm control, dietary guidance, influencing mineralization and implementation of health behaviors to control the caries process.

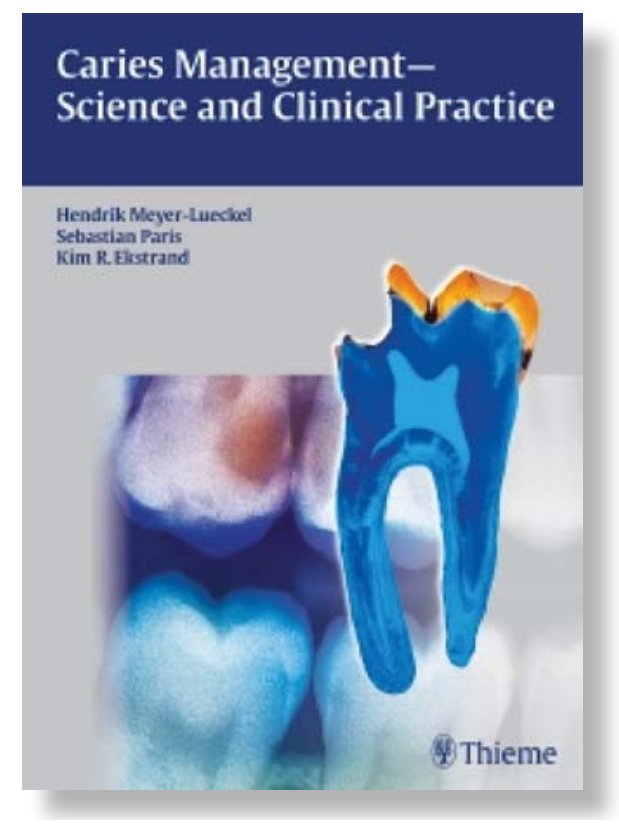

At the end of this part the book talks about the decision to treat dental caries and also about micro-invasive and invasive therapy.

The book includes three richly illustrated chapters on clinical practice which give a step by step overview of a number of clinical cases resolved by the authors of this book.

This book contains graphs, over 400 illustrations, tables and microscopic images, thus being one of the most relevant textbook in the field of contemporary cariology. It is addressed to those studying or working within dentistry.

https://doi.org/10.25241/stomaeduj.2015.2(2).bookreview.3

\footnotetext{
Florin Eugen

Constantinescu

DDS, PhD Student ROPOSTURO Holistic Dental Medicine Institute Bucharest, Romania drfflorin.constantinescu@gmail.com
}

The Book Review is drafted in the reviwer's sole wording and illustrates his opinions. 